\title{
Verbal and physical abuse against Jordanian nurses in the work environment
}

\author{
A.S. Ahmed ${ }^{1}$
}

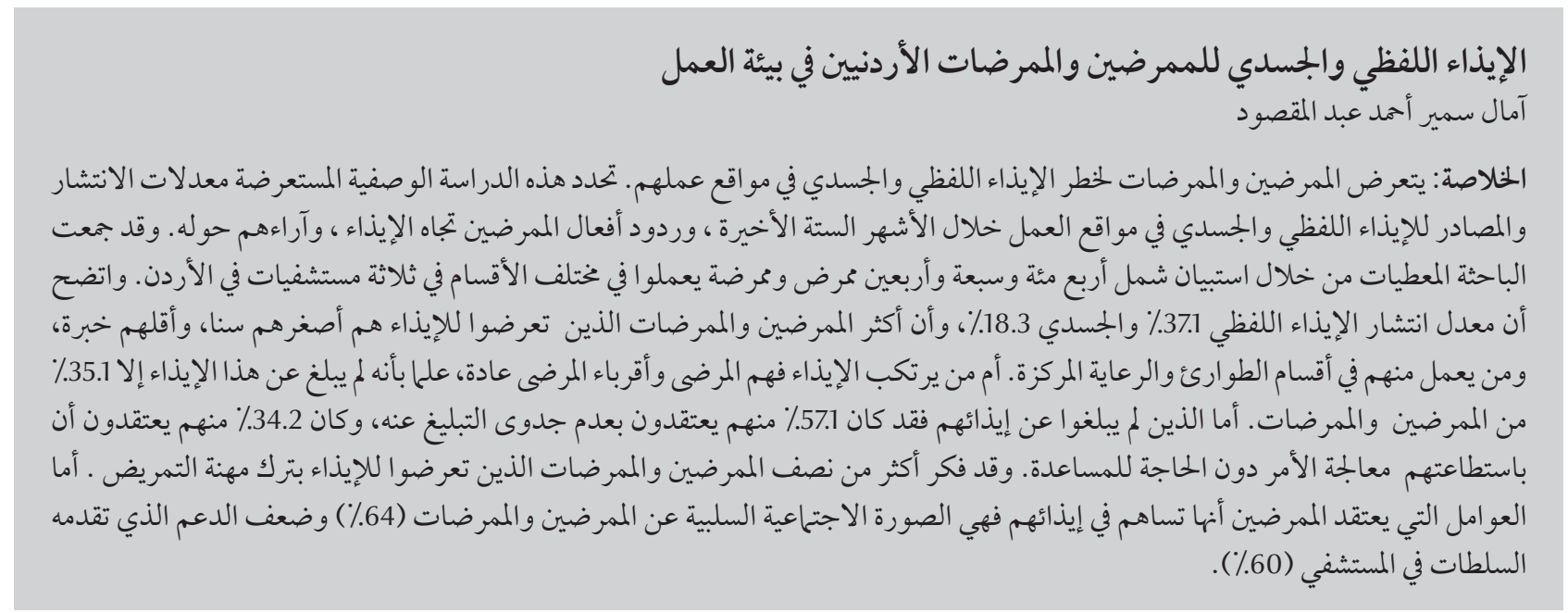

ABSTRACT This descriptive cross-sectional study determined the prevalence and sources of verbal and physical workplace abuse in the last 6 months, the nurses' reactions to abuse, and their opinions about it. Data were collected by questionnaire from 447 nurses working in various departments in 3 hospitals in Amman. The prevalence of verbal and physical abuse was $37.1 \%$ and $18.3 \%$ respectively. Younger, less experienced nurses and those in emergency and intensive care departments experienced more abuse. Patients and their relatives were the usual abusers. Only $35.1 \%$ of the abused nurses reported it; of those that did not, $57.1 \%$ thought it was useless to do so, while $34.2 \%$ thought they could handle the incident without help. Over half of the abused nurses considered leaving nursing and felt their quality of work decreased because of the abuse. Negative societal image of nurses (64\%) and poor support from hospital authorities (60\%) were the factors the nurses believed most contributed to abuse.

\section{Violences verbales et physiques contre le personnel infirmier jordanien en milieu de travail}

RÉSUMÉ La présente étude descriptive et transversale a permis de déterminer la prévalence et les sources de la violence verbale et physique en milieu professionnel au cours des six derniers mois, les réactions du personnel infirmier à ces violences et leur opinion en la matière. Les données ont été recueillies par questionnaire auprès de 447 infirmières affectées dans différents services de trois hôpitaux à Amman. La prévalence de la violence verbale et physique était de $37,1 \%$ et $18,3 \%$, respectivement. Le personnel infirmier plus jeune et moins expérimenté ou travaillant aux services des urgences et des soins intensifs était plus exposé à la violence. Les patients et leur famille représentaient des sources classiques de violence. Seuls 35,1\% des membres du personnel infirmier ayant subi des violences notifiaient l'incident ; parmi ceux qui s'abstenaient de le notifier, 57,1\% pensaient que la démarche était inutile et 34,2 \% qu'ils pouvaient gérer l'incident sans aide. Plus de la moitié du personnel infirmier ayant subi des violences envisageait de changer de métier et avait le sentiment que la qualité de leur travail était affectée en raison de cette violence. L'image négative du personnel infirmier dans la société (64\%) et le soutien médiocre consenti par l'administration des hôpitaux (60 \%) étaient les facteurs qui contribuaient le plus à la violence selon l'avis du personnel infirmier. 


\section{Introduction}

Today, health care personnel face harsher behaviour than ever before, all over the world. Of all hospital staff, nurses are most exposed to verbal and even physical abuse [1]. Nurses are the public face and intermediaries of the hospital, between patients and desk staff, technicians and doctors [2]. Their presence in stressful situations such as accidents, deaths, waiting to visit a doctor or transfer to a ward or another hospital exposes them to more abuse or harsh behaviour from patients or their companions than other hospital staff [3]. According to the Nova Scotia Association of Health Organizations, violence is defined as any behaviour that results in injury whether real or perceived by an individual, including but not limited to verbal abuse, threats of physical harm, physical harm and sexual harassment [4].

Exposure to abuse while carrying out their duties adversely affects nurses and may lead to loss of concentration while performing their tasks, inattention to ethical guidelines, higher numbers of careless mistakes, absence from shifts, repeated absenteeism, inattention to patients, reduction in job satisfaction, dislike of their job, and refusal to work in stressful wards. As a consequence of experiencing abuse in the workplace, a nurse may decide to relocate within a facility to another health care facility, or may leave nursing altogether. This may result in significant additional costs to treatment centres and the community $[1,2,5,6]$. Given the importance therefore of the problem and the fact that there are few data on abuse to nurses in Jordan, this study was conducted to determine the prevalence and types of abuse towards Jordanian nurses. Such information will be useful in understanding the source of verbal and physical abuses against nurses and identifying factors that contribute to workplace violence as well as developing effective methods to reduce abuse in health-care settings. This research has implication not only for nurses' health and safety but also, in the broader sense, for the profession's ability to attract and retain nurses within the health care system.

The aims of the study were to: i) determine the prevalence and sources of verbal and physical abuse against nurses and the factors associated with experiencing abuse, ii) identify the effects of abusive behaviour on nurses' health and their work performance, iii) assess the reaction of nurses to verbal and physical abuse, and iv) identify the opinions of nurses regarding abuse in the work environment.

\section{Methods}

\section{Study design, sample and setting}

This was cross-sectional descriptive study. The study was conducted among nurses in 3 hospitals (university, governmental and private) in Jordan from February to April 2010. Questionnaires were delivered to 500 nurses who were employed in different departments of the hospitals (medical, surgical, paediatric, maternity, intensive care, operating room, dialysis unit and emergency department) to collect data on verbal and physical abuse in the previous 6 months. Nurses were selected by systematic random sampling: 200 nurses from the university hospital, 150 from the government hospital and 150 from the private hospital.

\section{Data collection instrument}

The instrument (a self-completed questionnaire) was developed by the International Labour Office (ILO), International Council of Nurses (ICN), World Health Organization (WHO), and Public Services International (PSI) in $2003[7,8]$. The questionnaire was translated into Arabic and then backtranslated by the authors. The questionnaire contained a mixture of closed and open-ended questions.
The questionnaire consisted of 8 parts: Part I enquired about sociodemographic data of the nurses; part II assessed the most recent verbal or physical abuse episode experienced by the nurses in the previous 6 months. Being abused verbally was defined as being shouted at, sworn at, humiliated and threatened with harm; the nurses were asked to check whether they had experienced any of the verbally abusive behaviours listed from 4 different sources (colleagues, physicians, patients and patients' relatives); part III included similar questions to part II but concerned physical abuse. This was defined as being hit, kicked, pushed, scratched or pinched; part IV assessed the negative effect of abusive behaviour on the physical and psychological well-being of nurses as well as on their work performance and social life; part $\mathrm{V}$ assessed the nurses' reactions to verbal or physical abuse; part VI enquired about the reasons for not reporting an episode of verbal and physical abuse; part VII asked about the nurses' opinions on abuse in the work environment; part VIII assessed the factors contributing to violence and possible preventive measures to decrease abuse prevalence in hospitals.

The content validity of the instrument was assessed by 3 panels of experts. They were asked to review and evaluate the instrument for its clarity, validity, the rationality of the questions and their comprehensiveness, and the accuracy of the translation. Some revisions to questions were indicated. A pilot study was conducted with 20 participants, who were then excluded from the study, to determine the clarity of the instrument and the time required for each participant to complete the questionnaire. This resulted in some modifications being made. The Cronbach alpha score for all the scales was between 0.73 and 0.90 .

\section{Data collection}

Permission to conduct the study was obtained from the director of each hospital. Following that, the researcher 
scheduled a meeting with the head nurse and nursing staff of each unit to discuss the purpose of the study and the data collection process. The questionnaires were delivered to the nurses who had an interval of 1 week for their response.

\section{Ethical considerations}

The directors of the hospitals included in the study approved the research protocol. The participants were assured that their participation was voluntary and that they could withdraw from the study at any time. Participants' privacy was guaranteed as well as confidentiality. Written consent to take part in the study was obtained from individual respondents before data collection.

\section{Data analysis}

Data were analysed using SPSS, version 10. Descriptive statistics were used and frequencies, means and standard deviations (SDs) are presented.

\section{Results}

Of the 500 nurses, 447 completed the questionnaire, giving a response rate of $89.4 \%$.

\section{Characteristics of the nurses}

Just over half (56.8\%) the nurses were female. The mean age was 29.50 (SD 7.02 ) years and $80.7 \%$ were aged between 20 and 35 years. Almost half the nurses were married (46.8\%). The respondents were either registered nurses (60.6\%), associate nurses (26.4\%), assistant nurses $(8.5 \%)$ or midwives (4.5\%). They worked in the following departments: emergency department (17.0\%), operating room (13.2\%), medical ward $(7.8 \%)$, surgical ward (12.1\%), dialysis unit (5.6\%), intensive care unit $(24.4 \%)$, paediatric ward (10.1\%) and maternity ward (9.8\%). The highest portion of nurses (59.1\%) had a bachelor degree, followed by a 2-year diploma (37.8\%) and then a masters degree (3.1\%). About half of the participants (49.7\%) had less than 5 years experience in nursing.

\section{Prevalence of abuse}

Over half of the nurses (55.5\%) had experienced abuse in the past 6 months. The prevalence of verbal and physical abuse was $37.1 \%$ and $18.3 \%$ respectively. Patients' relatives and patients were the most frequent perpetrators of verbal and physical abuse (Table 1). The most frequent type of verbal abuse by patients' relatives was shouting and swearing $(75.3 \%$ and $44.5 \%$ respectively) and the most frequent type of physical abuse was pushing and hitting (24.4\% and $14.6 \%$ respectively). Nurse suffered humiliation as a form of verbal abuse more frequently from doctors (34.3\%) and were subject to malicious rumours more frequently from other nurses (26.5\%).

\section{Effects of and reaction to abuse}

Table 2 shows the negative effects of verbal and physical abuse on the nurses. Over $60 \%$ of verbally abused nurses reported that they had headaches, diffculty in sleeping and were tired after the episode $(66.3 \%, 60.8 \%, 61.4 \%$ respectively), while the majority of physically abused nurses reported that they felt tired and anxious $(80.5 \%$ and $73.2 \%$ respectively). Over half the verbally and physically abused nurses thought of leaving the profession $(57.8 \%$ and $59.8 \%$ respectively) and their quality of work decreased as reported by the nurses (51.8\% and $53.6 \%$ respectively).

Table 3 shows the reactions of the nurses to verbal and physical abuse. Over half of the verbally abused nurses (57.8\%) stated that they became "super-alert" (more careful and vigilant) following the abuse episode. In addition, the majority $(64.5 \%)$ tried to avoid the source of abuse. The majority of nurses (70.5\%) exposed to verbal abuse did nothing whilst over $43.9 \%$ of physically abused nurses reported the episode to a manager.

Of 87 nurses who reported the abuse, $59.8 \%$ said that they were very dissatisfied with the manner in which the incident was handled. The reasons for not reporting abuse incidents were: no evidence of injury (26.1\%); not important enough (19.3\%); feeling that reporting would be useless (57.1\%); and fear of blame or retribution (26.1\%) (Table 4).

Table 5 shows the nurses' opinions about abuse in the work environment: Over half of the nurses (54.1\%) expected to be abused at some time during their career, but $74.0 \%$ disagreed that this was because the nurse was not doing the job properly, while $44.7 \%$ agreed that abused nurses were likely to be victims because of personality traits. Most nurse $(63.3 \%)$ disagreed that, "Nurses abused without injuries should not report the incident", and $54.6 \%$ agreed there was a possibility of predicting a violent event. The majority of the nurses (63.1\%) believed that the safety set-up at work was not protective enough.

\section{Risk factor for abuse}

Female nurses, younger nurses (aged 20-30 years) and nursing aids were more at risk of violence $(61.3 \%, 81.0 \%$ and $62.1 \%$ respectively) than male nurses, older nurses and registered nurses (38.7\%, 1.2\%, and $8.1 \%$ respectively).

Over half of the nurses (52\%) who were exposed to violence were single (never married). Nurses who worked in the teaching university hospital were more at risk of violence than nurses working in the private and government hospitals (46.4\% versus $29.4 \%$ and $24.2 \%$ respectively). Working day shifts was associated with more violent incidents, while working night shifts was associated with less violent incidents (44.9\% versus $25.1 \%$ respectively). Intensive care units and emergency departments had a higher risk of abuse $(27.5 \%$ and $14.2 \%$ respectively) while dialysis and medical units have a lower risk of abuse (5.5\% and $7.3 \%$ respectively).

Participants were asked an openended question about the contributing factors to violence. Most of the contributing factors to violence 


\begin{tabular}{|c|c|c|c|c|c|c|c|c|}
\hline \multirow[t]{2}{*}{ Abuse type and source ${ }^{a}$} & \multicolumn{2}{|c|}{ Patients' relatives } & \multicolumn{2}{|c|}{ Patients } & \multicolumn{2}{|c|}{ Physicians } & \multicolumn{2}{|c|}{ Nurses } \\
\hline & No. & $\%$ & No. & $\%$ & No. & $\%$ & No. & $\%$ \\
\hline \multicolumn{9}{|l|}{ Verbal abuse $(n=166)$} \\
\hline Shouted at & 125 & 75.3 & 66 & 39.8 & 60 & 36.1 & 39 & 23.5 \\
\hline Sworn at & 74 & 44.5 & 39 & 23.5 & 24 & 14.5 & 16 & 9.6 \\
\hline Humiliated & 51 & 30.7 & 33 & 19.9 & 57 & 34.3 & 28 & 16.9 \\
\hline $\begin{array}{l}\text { Faced with inappropriate, nasty, hostile } \\
\text { behaviour }\end{array}$ & 59 & 35.5 & 30 & 18.1 & 22 & 13.3 & 22 & 13.3 \\
\hline Subjected malicious rumours & 30 & 18.1 & 14 & 8.4 & 17 & 10.2 & 44 & 26.5 \\
\hline Threatened with harm & 56 & 33.7 & 18 & 10.8 & 5 & 3 & 20 & 12.0 \\
\hline \multicolumn{9}{|l|}{ Physical abuse $(n=82)$} \\
\hline Hit & 12 & 14.6 & 10 & 12.2 & 2 & 2.4 & - & - \\
\hline Kicked & 6 & 7.3 & 8 & 9.8 & 1 & 1.2 & 1 & 1.2 \\
\hline Pushed & 20 & 24.4 & 18 & 22 & 3 & 3.6 & 5 & 6.1 \\
\hline Scratched & 3 & 3.6 & 6 & 7.3 & - & - & 3 & 3.6 \\
\hline Pinched & 5 & 6.1 & 6 & 7.3 & 1 & 1.2 & 2 & 2.4 \\
\hline
\end{tabular}

pertained to the negative societal image of nurses (64\%), poor support from higher authorities and the hospital administration for nurses (60\%), nursing shortage (56.5\%), lack of time and increased nursing workload (51\%), patients' physical and emotional condition (33.4\%), fear and anxiety of patients' relatives (30.6\%), high hospital costs (27\%), lack of security (24\%), lack of communication skills of nursing staff (18.7\%), lack of skills, experience and competency on the part of the nurse (15\%), and improper or incomplete information given to patients (14.8\%).

Suggested measures to reduce workplace violence were: improving security measures; enforcing polices and legal action for abuse; improving public awareness and societal image of the profession through the mass media, and providing training for staff on how to avoid and deal with workplace violence.

\section{Discussion}

The prevalence of verbal and physical abuse reported by the nurses in this study was $37.1 \%$ and $18.3 \%$ respectively; thus most abuse was verbal in nature. Previous studies have shown the same results, that verbal abuse occurs more often than physical violence $[3,5,9,10]$. In describing the perpetrators, patients' relatives and patients themselves were responsible for most of the verbal and physical abuse; but physicians

\begin{tabular}{|c|c|c|c|c|}
\hline \multirow[t]{2}{*}{ Reported effect ${ }^{a}$} & \multicolumn{2}{|c|}{ Verbal abuse } & \multicolumn{2}{|c|}{ Physical abuse } \\
\hline & No. $(n=166)$ & $\%$ & No. $(n=82)$ & $\%$ \\
\hline \multicolumn{5}{|l|}{ Negative effects on health } \\
\hline Headache & 110 & 66.3 & 35 & 42.7 \\
\hline Difficulty in sleeping & 101 & 60.8 & 30 & 36.6 \\
\hline Being tired & 102 & 61.4 & 66 & 80.5 \\
\hline Stomach pain & 72 & 43.4 & 27 & 32.9 \\
\hline Anxiety & 145 & 87.3 & 60 & 73.2 \\
\hline Fear & 66 & 39.8 & 40 & 48.8 \\
\hline \multicolumn{5}{|l|}{ Negative effects on work and social life } \\
\hline Decreased work productivity and quality & 86 & 51.8 & 44 & 53.6 \\
\hline Thoughts of leaving nursing & 96 & 57.8 & 49 & 59.8 \\
\hline Disturbed social life and relations & 70 & 42.2 & 30 & 36.6 \\
\hline Disturbed family life & 50 & 30.1 & 25 & 30.5 \\
\hline
\end{tabular}

${ }^{a}$ Not mutually exclusive. 


\begin{tabular}{|c|c|c|c|c|}
\hline \multirow[t]{2}{*}{ Reaction $^{\mathrm{a}}$} & \multicolumn{2}{|c|}{ Verbal abuse } & \multicolumn{2}{|c|}{ Physical abuse } \\
\hline & No. $(n=166)$ & $\%$ & No. $(n=82)$ & $\%$ \\
\hline Do nothing & 117 & 70.5 & 16 & 19.5 \\
\hline Avoid source of abuse & 107 & 64.5 & 30 & 36.6 \\
\hline Report abuse to a manager & 51 & 30.7 & 36 & 43.9 \\
\hline Reciprocate with similar behaviour & 57 & 34.3 & 27 & 32.9 \\
\hline Loss of appetite & 65 & 39.2 & 22 & 26.8 \\
\hline Perceive as a joke & 29 & 17.5 & 5 & 6.1 \\
\hline Use medicine for sleeping & 22 & 13.3 & 9 & 11.0 \\
\hline Go to a doctor & 14 & 8.4 & 17 & 20.7 \\
\hline Avoid thinking about or talking about the attack & 61 & 36.7 & 23 & 28 \\
\hline Be "super alert" vigilant and careful & 96 & 57.8 & 36 & 43.9 \\
\hline Take sick leave & 54 & 32.5 & 23 & 28 \\
\hline
\end{tabular}

${ }^{a}$ Not mutually exclusive.

themselves were also perpetrators of abuse to nurses; this is also consistent with other studies $[3,9,11]$. Nurses are usually the first persons that patients and their families meet. Therefore, they are often blamed for late or inadequate health services patients are often afraid that a physician may refuse to care for and treat them properly if they blame the doctors. In effect, nurses become the scapegoat [5]. In this context a previous study indicated that nurses in Jordan, as in other modern countries, are faced with heavy workloads, conflicts with other professionals, limited clinical autonomy, a non-supportive work environment, and feelings of inadequacy [12]. These conditions contribute to dissatisfaction, burn out and high rate of turn-over and attrition among nurses in Jordan [13].
Anxiety and tiredness were reported by the majority of nurses following exposure to verbal and physical abuse. In addition, over half of the nurses who were verbally and physically abused stated that the quality of their work had decreased and they had even thought of leaving the nursing profession. Verbal and physical abuse have been identified as leading to increased stress for victims, higher numbers of mistakes and contributing to a decreased sense of relaxation/well-being in the job setting, as well as low morale and job satisfaction [14-17].

The nurses reacted in a variety of ways to abuse: over one-third of verbally abused nurses reciprocated the abuse while $32.5 \%$ took sick leave. Over two-thirds avoided the abuse source

\begin{tabular}{lcc}
\hline Table 4 Reasons for not reporting an episode of verbal or physical abuse & \\
\hline Reason & No. $(\boldsymbol{n}=\mathbf{1 6 1})$ & $\%$ \\
Not considered important & 31 & 19.3 \\
No harm intended & 42 & 26.1 \\
Offender apologized & 58 & 36.0 \\
Felt ashamed & 20 & 12.4 \\
Reporting considered fruitless & 92 & 57.1 \\
Able to manage the incident without any help & 55 & 34.2 \\
Did not want it to appear on professional record & 42 & 26.1 \\
\hline
\end{tabular}

No. of nurses who reported an episode of abuse $=87 / 248$ (35.1\%).

35 out of 87 (41.1\%) of the nurses were satisfied with the method of handling of abuse following reporting of incident, the rest were not satisfied. while $57.8 \%$ stated that they became "super alert". It is surprising to note that only $35.1 \%$ of abuse incidents were reported by nurses. This is consistent with the high rates of underreporting identified in other studies [18-20]. The most common reason for not reporting abuse was that it would be useless In addition, over one-third of abused nurses stated that the situation was handled/ resolved and the offender apologized. Some researchers believe that such action by nurse victims somehow mitigates the circumstances for violence, and there is a widely held belief patients who were abusive are somehow not competent due to their illness [21]. May and Grubbs [22] argued that the majority of nurses accepted the presence of abuse as a feature of their occupation and believed that reporting would be time-consuming and fruitless $[11,14]$. The results also showed that less experienced nursing personnel were more likely to suffer an episode of abuse. It may be that nurses can predict and manage tense situations better as their experience increases. However, the findings of Hodgson et al. [23] conflict with this; they reported that nurses who had more than 20 years of experience were exposed to more violence. The difference is likely due to the fact that they examined the lifetime incidence of 


\begin{tabular}{|c|c|c|c|}
\hline Opinion & $\underset{\%}{\text { Agree }}$ & $\begin{array}{l}\text { Disagree } \\
\%\end{array}$ & $\begin{array}{l}\text { Don't know } \\
\%\end{array}$ \\
\hline Nurses should expect to be abused some time during their career & 54.1 & 40.3 & 5.6 \\
\hline The staffing pattern \& physical set-up at work protect nurses & 23.3 & 63.1 & 13.6 \\
\hline Abused nurses are not doing their job properly & 11.4 & 74.0 & 14.6 \\
\hline Abused nurses are likely to be victims because of personality traits & 44.7 & 35.8 & 19.5 \\
\hline A competent/qualified nurse can predict a violent episode & 54.6 & 27.5 & 17.9 \\
\hline Nurses abused without injury should not report the incident & 29.5 & 63.3 & 7.2 \\
\hline $\begin{array}{l}\text { Nurses should have the right to legal action even when the abuser is a } \\
\text { patient }\end{array}$ & 62.6 & 18.6 & 18.8 \\
\hline Nurses taking legal action are at risk of losing their job & 42.3 & 32.9 & 24.8 \\
\hline Patients should be responsible for all their behaviour & 56.6 & 29.8 & 13.6 \\
\hline
\end{tabular}

workplace violence, not just a 12-month period, and those who had worked longer would be expected to have experienced more violent events.

In relation to nurses position and abuse, the nurses in lower positions experienced more frequent abuse than others. This may be due to their close contact with patients or their family members, or due to the way they treated patients. As Adib et al. [11] and Ayrancy [24] noted, the frequency of abuse is greater towards nurses who perform the first treatment on patients than towards other nurses who care for the same patients later.

The risk of experiencing abuse was higher among nurses who worked in intensive care units and emergency departments. Factors such as patient pain and discomfort, family member stress due to the patient's condition and fear of the unknown might increase emotional tension among patients and visitors in emergency departments and intensive care units. Moreover, frustration and vulnerability felt by patients and their families may be manifested in physical and verbal abuse against nursing staff. In this context, Shoghi et al. also found that nurses working in emergency and intensive care units were subjected to more abuse than those in other departments [1].

\section{Study limitations}

This study was carried out only in 3 hospitals in Jordan. Therefore, the results cannot be generalized to all nursing staff working in other hospitals. The data were collected retrospectively, i.e. up to 6 months after the episode of violence, and may therefore suffer from recall bias, or lack of willingness to share private information. However, the questionnaire only asked participants to recall experiences from the past 6 months and the level of consistency suggests that the reports were valid. Furthermore, the $89.4 \%$ response rate also indicates cooperation from the target group. Thus, the potential bias mentioned above is likely to be small.

\section{Conclusions}

Nursing is a profession faced with many challenges emanating from the environment of hospitals; they have to deal with sick patients and their stressed families and the death of a patient and the subsequent grief, as well as the stress that shift work puts on the families of nurses and the restrictions it places on their social activities. Over and above that they also often have to deal with being exposed to and a victim of abuse.

The findings of this study underscore the potential risk to nursing staff. Many participants in the study experienced workplace abuse, but only a minority of these reported the episode and of those who did, most were very dissatisfied with the manner in which the abuse episode was handled. While the formal systems for dealing with reports of violence by nurses in the hospitals were not assessed, the general view of the nurses that to complain was fruitless and the dissatisfaction of those who did complain suggests that nurses are not fully confident of the systems in place. Given the effect that such abuse can have on nurses' well-being and also patient care, it is important to have and implement a strict policy on abuse or the threat of abuse in all healthcare environments. At the same time all staff, including nurses, must be adequately informed of the policies so that they are prepared in the event of an incident. They need to know how and to whom to report as well as how to document problem situations. Nurses should be reassured that reporting threatening behaviour will not result in reprisals and that appropriate action will be taken to deal with abusers. A zero tolerance policy will help to raise the awareness of abuse and emphasize the importance of communicating violent episodes A safe and secure employment environment is an irrefutable right of all nurses and is essential for the provision of quality care.

\section{Acknowledgements}

It would not have been possible to complete this survey without the cooperation and support of the leadership of the nursing departments at the hospitals. 


\section{References}

1. Shoghi $\mathrm{M}$ et al. Workplace violence and abuse against nurses in hospitals in Iron. Asian Nursing Research, 2008, 2:184-193.

2. Celik $\mathrm{S}$ et al. Verbal and physical abuse against nurses in Turkey. International Nursing Review, 2007, 54:359-366.

3. Kwok RP, Law YK, Li KE. Prevalence of workplace violence against nurses in Hong Kong. Hong Kong Medical Journal, 2006, 12:6-9.

4. Violence in the workplace: a resource guide. Halifax, Registered Nurses' Association of Nova Scotia, 1996.

5. Lin $\mathrm{Y}$, Liu $\mathrm{H}$. The impact of workplace violence on nurses in South Taiwan. International Journal of Nursing Studies, 2005 42:773-778.

6. Arenetz JE, Arenetz BB. Violence towards health care staff and possible effects on the quality of patient care. Social Science \& Medicine, 2001, 52:417-427.

7. International Council of Nurses. International perspectives. International Nursing Review, 2003, 50:196-200.

8. Joint Programme on Workplace Violence in the Health Sector Workplace violence in health sector. Country case studies research instruments. Survey questionnaire. Geneva, International Labour Office, International Council of Nurses, World Health Organization, and Public Services International, 2003.

9. Oweis A, Diabat K. Jordanian nurses perception of physicians verbal abuse: findings from a questionnaire survey. International Journal of Nursing Studies, 2005, 42:881-888.

10. Lanza ML. Reducing violence against nurses: the violence prevention community meeting. Issues in Mental Health Nursing, 2009, 30:745-750.

11. Adib SM et al. Al-Raqem M. Violence against nurses in health care facilities in Kuwait. International Journal of Nursing Studies, 2002, 39:469-478.

12. Al-Ma'aitah R et al. Effect of gender and education on quality of nursing work life of Jordanian nurses. Nursing and Health Care Perspectives, 1999, 20:88-94.

13. Armstrong $\mathrm{M}$ et al. Determinants and consequences of burnout: a cross-cultural comparison between Canadian and
Jordanian nurses. Health Care for Women International, 1994, 15:413-451.

14. Pejic AR. Verbal abuse: a problem for pediatric nurses. Pediatric Nursing, 2005, 31:271-279.

15. Celebioglu A. Violence experienced by Turkish nursing students in clinical settings: their emotions and behaviors. Nurse Education Today, 2010, 2:30-38.

16. Camerino $\mathrm{D}$ et al. Work- related factors and violence among nursing staff in the European next study: a longitudinal cohort study. International Journal of Nursing Studies, 2008, 45:35-50.

17. Abu Airub RF. Khalifa MF, Habbib MB. Workplace violence among Iraqi hospital nurses. Journal of Nursing Scholarship, 2007, 39:281-288.

18. Duncan SM et al. Nurses' experience of violence in Alberta and British Columbia Hospitals. Canadian Journal of Nursing Research, 2001, 32:57-78.

19. Bayman PA, Hussain T. Receptionists' perceptions of violence in general practice. Occupational Medicine, 2007, 57:492-498.

20. Gacki-Smith J et al. Violence against nurses working in US emergency departments. Journal of Healthcare Protection Management, 2010, 26:81-99.

21. Howells J. Verbal abuse. British Journal of Perioperative Nursing, 2000, 10:508-511.

22. May DD, Grubbs LM. The extent, nature, and precipitating factors of nurse assault among three groups of registered nurses in a regional medical center. Journal of Emergency Nursing:JEN, 2002, 28:11-17.

23. Hodgson MJ et al. Violence in healthcare facilities: Lessons from the Veterans Health Administration. Journal of Occupational and Environmental Medicine, 2004, 46:1158-1165.

24. Ayrancy U. Violence toward health care workers in emergency departments in west Turkey. Journal of Emergency Medicine, 2005, 28:361-365. 